\title{
Autism then and now: Society and science
}

\author{
Florence Neymotin* \\ Nova Southeastern University, 3301 College Avenue, Fort Lauderdale FL, 33314, USA
}

\begin{abstract}
Autism is a very complicated diagnosis, both with respect to recent discoveries on its functional genetic basis, as well as the historical path its analysis has taken. The present work takes a unique perspective in examining how we may view changes in the development and history of autism through a broader lens that incorporates the often ignored bi-directional interaction between science and cultural attitudes, and what this may imply for future research and treatments.
\end{abstract}

\section{Introduction}

Autism diagnoses are increasing in our society, and current estimates have 1 in 68 children being placed on the spectrum [1]. Issues surrounding this condition reach the heart of our culture, with movies about Autism or containing Autistic characters now treating these situations in a similar fashion to any other fundamental aspect of family functioning [2]. In light of this increasing prevalence of the diagnosis of Autism, it is even more crucial that we understand its etiology, mechanisms, and, if considered a disease or impairment, what treatments are effective. Unfortunately, our knowledge cannot exist apart from a functional societal and cultural framework.

While, by most accounts, we have made great strides forward in our understanding of the fundamental aspects of Autism in all its forms and categorizations, it is also the case that our understanding has followed a very clear and historically determined path. In particular, I argue that the way we research and understand Autism is strongly driven by prevailing social and political trends, even more than by actual changes in the available scientific evidence, or technology necessary for these developments. While certain changes are obviously necessary for advancing particular aspects of research, one in particular being genomic sequencing, the overall framework within which we have worked has not changed as fundamentally over time as much as our societal changes have guided what information we selectively receive and retain for the future. It is also true that, for better or for worse, we often engage in selective historical revision, with the backwards induction of historical entities for Autistic traits as one particular example [3].

Consequently, I have chosen to organize this particular essay, which focuses in large part on the innovations of the last thirty years in the development and history of Autism research, by category rather than chronologically. It will become apparent that many notions regarding the causes of Autism have been present the whole time, but changing trends in either the science or the culture have influenced which ideas were acceptable or not, more than the correctness of the science.

\section{Results and discussion}

\section{Nomenclature: The heart of the debate}

In some sense, semantic debates over what to call something are more important than they at first seem. In the case of autism, it is not even clear whether it should be called a "condition," a "disease," or requires a completely different typology. The choice of terms has depended to a very large extent on what is thought at the time to be stigmatizing, as well as allowing individuals to have access to care in the best fashion possible. Let me begin by defining the characteristics typically ascribed to Autism, and moving on to a more involved discussion on the topic.

\section{Autism defined: Characteristics}

In some sense, Autism is defined as much based on famous historic discussions as by discoveries of comorbidities or genetic linkages. While there were a number of therapists who studied Autism, the accounts of Kanner and Asperger were the most vivid, and so theirs are the names and definitions that have survived on to today [4]. While Earl preceded Kanner by nine years, describing "mentally-retarded children with catatonia," whom we may now consider severely Autistic, and Langdon Down in 1887 described what we may now consider "Autistic savantism" [4], it is Kanner's definition that has become the most widespread.

Kanner's book "Autistic Disturbances of Affective Contact" was based on a study at the Maudsley psychiatric institute, where he examined children who he said were very "alone" and usually exhibited low IQs [5]. When describing his first test subject, Donald T., Kanner said he was a remarkable little boy who was happiest when left alone. He did not seem to notice when someone entered or left the room he was in, and he was indifferent to visiting relatives, potential playmates, and he even failed to pay the slightest attention to Santa Claus in his full costume. When petted he showed no apparent affection and he gave the impression of being self-sufficient. At the age of two he developed an obsession for spinning blocks and pans and virtually all round objects that could be spun. A spinning pan for instance, could keep him fascinated for hours and, when interfered with, he had destructive temper tantrums. The majority of his actions were endless

Correspondence to: Florence Neymotin, Nova Southeastern University, 3301 College Avenue, Fort Lauderdale FL, 33314, USA, E-mail: fneymotin@nova.edu

Key words: autism, cultural attitudes, historical path, society

Received: September 19, 2016; Accepted: October 03, 2016; Published: October 06,2016 
repetitions performed in exactly the same way as they had been carried out originally. Furthermore, he never spontaneously spoke just to chat or to share his thoughts. When he spoke, he seemed either to ejaculate irrelevant utterances randomly, such as 'chrysanthemum' or to parrot what he had heard said to him at some other time [6].

Around this same time, Hans Asperger had four children in his study whom he labeled as socially isolated, poor at empathizing, and tended to intellectualize their emotions and use formalistic dialogues. He called them "little professors" [7]. In contrast to Kanner's group, we now know that individuals with "Asperger's syndrome" tend to be less withdrawn in social groups and are often difficult to diagnose in the first year of life. They also have less difficulty with verbal problems. Interestingly, Wolff initially talked about a "schizoid disorder" that was very similar to what we now think of as Asperger's syndrome [8].

It was not until the 1980s that Lorna Wing's work clarified the meaning of both Kanner's and Asperger's patients. She observed children who had unusual patterns of social interactions, verbal and nonverbal communication and imaginative activities. This then became the precursor for diagnostic standards of Autism, and also allowed for a more inclusive classification of both Autism and Asperger's syndrome [9]. It is notable that one individual's personality and importance in the field served to highlight and focus attention in a field that was just beginning to take form.

In terms of the specific characteristics that have been used as diagnostic criteria, Asperger's syndrome presents as individuals being socially naïve, behaviorally rigid, having bad inflection and prosody, a rate of speech not quite right and volume often too loud or quiet for the area, talking too much, and having a number of specialized interests. It may take longer for their motor skills to develop, and they may be awkward and uncoordinated with some neurological deficits in visual motor and visual perceptual skills [7]. Some typical signs that are checked during an evaluation are normality of gaze, gestures, understanding nonliteral language, inflection, taking turns in conversation and speech cues, content coherence, perseveration on certain topics that interest them, understanding the language of emotions, and whether they understand the rules of conversation and reciprocity.

\section{DSM changes}

Related to the debate over the definitions of Autism has been the problem of how to formally diagnose Autism in a medical sense, as codified by the Diagnostic and Statistical Manual and the International Classification of Diseases. Autism first appeared in the DSM III, and this was in a rigid format and theoretical enough as to make it almost impossible for anyone to be classified as Autistic [10]. The huge increase in "diagnosed" rates of Autism after the publication of the DSM IV is, in part, a simple reflection of the more inclusive standard of diagnostic criteria In particular, not every single aspect must be met in order to classify someone as having Autism. Asperger's syndrome, which was briefly recognized as a separate disorder in the DSM IV-R, has since been deleted in the DSM V [11].

Just as a great deal of controversy surrounded the move from version III to IV, with an increase in inclusiveness, so too has the movement from DSM IV to DSM V been accompanied by massive amounts of discussion and disagreement in the psychological community [8]. The "draft" version of DSM V drew hundreds of articles commenting on issues, including:

1. The lack of a specific category for Asperger's syndrome, so that these individuals might become ineligible for treatment.

2. Dropping certain diagnostic criteria and not providing a list of particular behaviors so that only highly trained specialists would be able to diagnose Autism.

3. The requirement that individuals be diagnosed in childhood and again in adulthood, which is clearly a problem if the patient did not have access to care or to caregivers who knew to take them in to be tested as a child.

4. Pushing the diagnosis towards being over age three. This was suggested because of the stability of the disorders generally. However, it is also true that early intervention is seen to be highly effective, and can even start based on tests conducted as early as eighteen months using Baron-Cohen's early diagnostic method established in 1996 [4]. Without including early ages, this type of early intervention will be less likely to be provided [12].

\section{Childhood schizophrenia or schizoid personality}

This raises an interesting question: prior to the development of a firm conception of Autism, what did society and experts think of children who exhibited these characteristics? Some of the earlier scientific accounts of Autism showed a belief that it was a form of childhood schizophrenia or "dementia praecox" [13]. Of course, when first introduced by researchers in the Maudsley hospital, this was considered appalling because of the contemporary conception of childhood as a type of innocence and schizophrenia and related illnesses were not things that innocents suffered from [3]. Although it is possible that Autism was, at that time, rare enough as to avoid description, I would argue that perhaps the functional fixedness in society in believing in childhood saintliness made it difficult to see any issues of this form.

Whether life imitates art, or whether art imitates life, once the idea of childhood schizophrenia was introduced, it began to take hold. In fact, one of the first two journals devoted to the study of Autism also dealt with schizophrenia and was called "The Journal of Autism and Childhood Schizophrenia" [3]. While the initial link between Autism and schizophrenia is not commonly remembered in modern times, it is true that the very word "Autism" was first coined by the psychiatrist Eugene Bleuler in 1910 [13,14]. By 1979, however, it was already deemed to be incorrect to think of Autism as schizophrenia, and subsequent linkages began to disappear from the literature [11]. Perhaps it was also the case that preserving childhood innocence once again took over as an imperative.

Moving to modern times, now that genetic testing is available to identify gene loci and risk factors associated with Autism, it has been discovered that several of these locations relate also to schizophrenia [15]. It would appear then that the initial assumption that Autism is a form of schizophrenia, once rejected as inappropriate, has now found new credibility. This is but one example of how conventional thinking has come full circle in our understanding of the ways that individuals experience Autism.

\section{Autism and related syndromes}

While I have introduced the concept of "Autism" generally, what it actually encompasses has evolved a great deal in the last century. Asperger's syndrome, discussed previously, may be one related part of Autism, but it is certainly not the only illness that shares characteristics or has been considered within a common umbrella. In fact, we are now finding that there may be hundreds of different genetic loci responsible 
for the biological representation of "Autism" [16]. Similarly, we are finding thousands of at-risk gene locations $[17,18]$. This is leading to the understanding that Autism is both highly complex in a genetic sense, as well as the possibility that there may not in fact be one typology which we can call "Autism." That is, there is no single genetic pathway for Autism. Rather, it serves as an umbrella for a wide variety of genetic combinations resulting in similar phenotypic representations [19]. Autism appears to elude our attempts at a simple and singular categorization. With further technological advances, rather than helping us to tease out the common factors; we have begun to find an increasing amount of complexity. Notice, however, that this pattern of seeking simplicity and having the problem of multiple representations is not a new one.

When Kanner [6] first presented his idea of Autism, it is noteworthy that he did not mention the idea of tuberous sclerosis-a particular disease which, if untreated by a special diet, can look similar to our conception of Autism. [4] notes that this was not mentioned, presumably because Kanner believed that what he was discovering was very different than what had been previously observed. I would contend that he also was attempting to clearly categorize and conceptualize Autism, rather than allowing it to blend together in an "umbrella" fashion and be lost in its complexity.

Rett's Syndrome is another illness that has been mentioned in relation to, and sometimes even under the umbrella of, Autism. In this case, the patient-usually a girl because the boys tend to die before birth-seems fine until the preschool years, and then suffers a massive degeneration with social unresponsiveness, seizures, and developmental delay [8]. While this was initially considered a form of Autism, new genetic tests have deemed-based perhaps on subjective delineations of the exact boundaries of Autism - that this is a different disorder [8]. Similarly, in Childhood Disintegrative Disorder (CDD) earlier noted by Heller in the context of "dementia infantilis" [3] children appear functionally typical until the age of three or four, when they start to display characteristics and behaviors similar to Autism [8]. Due to increased genetic understanding, CDD is now also thought to operate with a mechanism distinct from Autism.

While Rett's, CDD, and Tuberous Sclerosis are arguably outside the Autism umbrella, efforts have been made to include other kinds of conditions, deemed high-functioning Autism, Asperger's syndrome (mentioned previously), and Pervasive Developmental Delay (PDD) or "atypical Autism." In the case of high-functioning Autism, there is usually no cognitive deficit, and verbal issues are not present. What makes this different from Asperger's in the official definition is simply that a delay in language acquisition was present during the time when the child was younger. Otherwise, the two are functionally identical, and in fact, comorbidity studies with other illnesses often treat them as identical [7]. Clearly this is confusing, both for laypeople and for insurance companies. The question is, should a person who did not have a significant developmental delay earlier in life-or perhaps did have this problem but was not diagnosed-be denied medical coverage and treatment for the same issues? [11]. Individuals with Asperger's, while often high functioning and quite successful, may still have a number of difficulties that are apparent within the general Autism disorder, and may also have the need for adequate care.

In Pervasive Developmental Disorder (PDD), officially recognized in 1994 [7], individuals do not "quite" meet the definition for classical Autism, but have difficulties communicating and restricted behavior. This atypical Autism can now be considered a part, along with older definitions of Autism, to be the Autism spectrum, and explains why we collectively talk about Autism Spectrum Disorder (ASD) [8].

\section{The mother's role}

While the nature-nurture debate is far from being resolved, it does seem apparent that environmental, epigenetic, and genetic factors are at play in many illnesses. Autism appears to follow the rule rather than be the exception. With this in mind, the role of mothers both during gestation, as well as childhood, has been the subject of much debate. It may be that trends in how a mother's role has been perceived in Autistic development closely parallel those of the position of women in society more generally. These points to some important harbingers for possible future change.

\section{Psychoanalysis and the "Frigidaire Mother"}

While Kanner initially believed that the children he observed were linked by genetic factors, he was also influenced by the psychoanalytic theories of the time. This meant that Autism treatment went through a period of being subject to clinical intervention in which psychoanalysts placed blame on the mother (or family environment), and took credit when there was improvement. This imbalance between risk and reward was clearly to the benefit of and therapists, and against families. Mothers were - cruelly by modern perspectives - branded as "Frigidaire" moms, and their coldness and lack of empathy for their child was blamed for the lack of neurotypical development. This movement went so far as to, under the guidance of Bettlemein, remove children from their homes and put them into treatment facilities which supposedly had a better environment for them [20].

This trend went on for some time, until the "British Society for Autistic Children" now called "The National Autistic Society" was formed [4], and the related "Autism Society for America" was formed in 1964. The idea was to support a link between biology, rather than cold mothers, and Autism [21]. Parents and others were beginning to believe that the coldness of caregivers was not to blame for their children's issues. The rise of behaviorism helped develop therapy techniques that were more successful. Ivar Lovaas was one of the main proponents of this movement, teaching life skills by breaking them down into small chunks and then applying them in a natural situation [22]. This pro-parent-philosophical trend has generally continued until very recently.

\section{Prenatal environments matters}

The recent movement towards scrutinizing the prenatal environment is scientifically supportable. However, it comes at a time when women are starting to drop out of the work force at the highest levels, breast feeding is being touted as the most important aspect of bonding - as in "breast is best" [23], and there is a worldwide return to baby-carrying and "kangaroo care." Therefore, the developing research on prenatal environments should be interpreted keeping these societal trends in mind.

In particular, there has been an effort to determine which proteins and molecules can have a prenatal effect on Autistic development. A key paper by S. Baron Cohen, et al. [24] examined the presence of steroidogenic compounds in affecting Autistic behavior. The authors did indeed find a link between cortisol, the stress hormone, and increased rates of Autism. They also posited a possible role for estradiol responsible for "masculinizing the brain" in other species as another route. What is interesting and important about this work is that it revisits an earlier theory in which Autism is thought of as an extreme 
masculinization of the brain [25].

1. The implication of this work is that women who have too much cortisol (or "stress") may be an increased risk for having Autistic children.

2. Taking an expansive view, I believe it may be just a small step to argue that the movement of women into the workforce in greater numbers in the eighties and the resulting higher levels of stress reflected also in increasing rates of vascular diseases for women [26] can be responsible for higher rates of Autism. What does this mean for a society that spent millennia having women "gather" and men "hunt"? What is the effect of women stepping outside of their traditional roles? Much is still unknown about the effects on the population as a result of changing societal norms and gender roles. On the flip side, women dropping out of the work force is politically fraught, and some could use such statistics and an interpretation of Autism as a neuro-immune disease as a rationale for more traditional roles.

\section{Moving forward: Comorbidity}

One of the difficulties with Autism is determining the difference between symptoms and co-morbid conditions. This often boils down to the benefits and costs of having overly specific diagnostic criteria versus "lumping" many different aspects together [10]. It is important to determine whether one is treating symptoms or a related condition, since treating a co-morbid condition may or may not be helpful for treating the primary issue of concern, and, in some cases, it may actually exacerbate the underlying problem [19]. Additionally, given the ambiguity in what Autism even means, and the social construction necessary to make the decision, it is not particularly surprising that many individuals are averse to being labeled as "Austistic."

As one example of a co-morbid condition, we can take the case of epilepsy. While Kanner initially believed that seizures were a characteristic of Autism [27], we have now instead moved towards categorizing them as co-morbid with autism [28]. Notice that, since the current conception of Autism is a neuro-immune disorder, a link with epilepsy is not particularly surprising. If Autism affects the limbic system, cerebellum and frontal and temporal cortex [29], it stands to reason that it might correlate with the onset of other conditions related to the same locations in the brain. Nevertheless, it is still difficult, even today, to draw the line between co-morbid conditions and those which are symptomatic of the Autism.

Some other illnesses that are co-morbid with Autism and have received a large amount of attention over the years are Obsessive Compulsive Disorder, Anxiety, Mood Disorders, and Tourette's Syndrome [7]. In characterizing Autism as a neurodevelopmental disorder, it is logical to see why these diseases would be grouped together. Stemming from the connection between these particular connections is the potentially promising method of using oxytocin to treat Autism.

While it is unclear whether oxytocin has an effect primarily through the plasma or the brain-since it exists in both areas and its half life is short enough to be difficult to trace-it is clear that there are measurable effects as a result of the nasal sprays that have been employed [30]. A related and very interesting issue is whether oxytocin operates by affecting the higher-level cognitive functions, such as trust and reciprocity, or by using a more bottom-up approach and affecting anxiety directly. In this case, perhaps treating the co-morbid conditions is indeed a way to treat a symptom of the illness itself.
As an aside, I would note that, once again, we can see strong political influences at play here regarding the use of oxytocin to treat Autism. It was previously thought that oxytocin was exclusively present in female hormones from reproduction and milk production. The current movement towards "breast is best" [23] mirrors this idea that mothers are responsible for nurturance and the simulated version of oxytocin being provided is in keeping with the same sociopolitical trend.

In addition to being a neuro-immune disorder, Autism has also been examined as an "inflammatory" illness in the brain. In this vein, a number of interesting co-morbid conditions have been discovered. Melke [31] found that melatonin levels tend to be low in individuals with Autism. In some ways, this makes sense, since melatonin is an antioxidant and important for immunity as well as being a key aspect of circadian rhythm regulation.

Given the view of Autism as having an issue with inflammation in certain parts of the brain [32], not having enough melatonin may exacerbate the inflammatory response. It was also noted that increasing levels of melatonin was helpful in treating insomnia in older patients with Autism, who frequently have problems with melatonin regulation. However, its use in younger children has yet to be tested. Once again, it is unclear whether low levels of melatonin are a part of the illness, a causal factor, or a related comorbid issue, particularly since relatives of individuals with Autism and low melatonin were likely themselves to have low melatonin.

On the other hand, cytokine regulation has been tried as a treatment method, and has been found to be very helpful in alleviating the symptoms of Autism, presumably through the channel of reducing inflammation in the immune system [32]. Immune system regulation as a factor for ASD has also gained some traction when considering that allergies have been found in numerous studies to relate to Autism $[28,33,34]$. Notice that the idea of having an inflammatory response may be just one type of Autism among the many different phenotypes $[19,35]$. Examined this way, one could ask whether children with heightened immune systems higher inflammation are also the ones who have increased risk to environmental triggers. Unfortunately, the inflammation hypothesis came slightly earlier than the trend towards increased focus on locating genetic factors, and the political climate at that time may have been less conducive to asking that type of a question.

Consistent with the idea of inflammation and allergies, one area of research that has come up is the relationship with digestive tract issues [36]. As a problem with mitochondrial dysfunction in the brain, this could cause some of the symptoms of Autism, and in the gut this can create issues such as constipation. If mitochondrial dysfunction is the common pathway, not all mitochondria in the body need to be affected. However, if the ones in the brain are, then this would indeed be a good example of a co-morbid condition, rather than a characteristic of Autism. As an alternative, Angelidou [37] note that the main issue may be mast cells that disrupt the gut to blood-brain barrier. In that case, with mast cells as the causal pathway, it would be less clear whether the gut issues are co-morbid or an additional symptom.

\section{Conclusion}

The present analysis has presented a guided view of research in the area of Autism with a particular focus on the last few decades. While it is unclear which direction we may move in the future, historic patterns and societal links with research choices have been highlighted in order clarify the difference between social constructions and true-false 
dichotomies. With the amount of interesting and important research on the forefront, it is crucial to have a clear vision of what research has actually demonstrated, as well as what may possibly be occurring in the near future. Some suggestions have been posited for future discussion.

\section{References}

1. CDC estimates 1 in 68 children has been identified with autism spectrum disorder (2014) Disabilities Monitoring Network, 14 sites, United States, 2008. Morbidity and Mortality Weekly Report 61.

2. Bhattacharya A (2015) Autism in Movies- A Paradigm Shift. Indian Journal of Growth, Development and Behavioral Pediatrics 11: 27-31.

3. Wolff S (2004) The history of autism. Eur Child Adolesc Psychiatry 13: 201-208. [Crossref]

4. Wing L (1997) The history of ideas on autism: legends, myths and reality. Autism 1: 13-23.

5. Goldstein S, Naglieri JA, Ozonoff S (2009) Assessment of Autism Spectrum Disorders. Guilford Press.

6. Kanner L (1943) Autistic disturbances of affective contact. Nervous Child 2: 217-250.

7. Klin A (2003) Asperger syndrome: an update. Rev Bras Psiquiatr 25: 103-109. [Crossref]

8. Volkmar FR, Reichow B, McPartland J (2012) Classification of autism and related conditions: progress, challenges, and opportunities. Dialogues in Clinical Neuroscience 14: 229-237. [Crossref]

9. Wing L (1981) Language, social, and cognitive impairments in autism and severe mental retardation. Journal of Autism and Developmental Disorders 11: 31-44. [Crossref]

10. Volkmar FR, McPartland JC (2014) From Kanner to DSM-5: autism as an evolving diagnostic concept. Annu Rev Clin Psychol 10: 193-212. [Crossref]

11. Verhoeff B (2013) Autism in flux: a history of the concept from Leo Kanner to DSM5. Hist Psychiatry 24: 442-458. [Crossref]

12. Wing L, Gould J, Gillberg C (2011) Autism Spectrum Disorders in the DSM-V: Better or worse than the DSM-IV. Research in Developmental Disabilities 32: 768-773. [Crossref]

13. Bleuler E (1911) Dementia praecox oder Gruppe der Schizophrenien. Int Univ Press.

14. Greydanus D, Toledo-Pereyra L (2012) Historical perspectives on autism: Its past record of discovery and its present state of solipsism, skepticism, and sorrowful suspicion. Pediatric Clinics of North America 59: 1-11.

15. Ylisaukko-oja T, Nieminen-von Wendt T, Kempas E, Sarenius S, Varilo T, et al. (2004) Genome-wide scan for loci of Asperger syndrome. Mol Psychiatry 9: 161-168. [Crossref]

16. Betancur C (2011) Etiological heterogeneity in autism spectrum disorders: more than 100 genetic and genomic disorders and still counting. Brain Research 1380: 42-77. [Crossref]

17. Sanders SJ, Murtha MT, Gupta AR, Murdoch JD, Raubeson JJ, et al. (2012) De novo mutations revealed by whole-exome sequencing are strongly associated with autism. Nature 485: 237-241. [Crossref]

18. O’Roak BJ, Vives L, Girirajan S, Karakoc E, Krumm M, et al. (2012) Sporadic autism exomes reveal a highly interconnected protein network of de novo mutations. Nature 485: 246-250. [Crossref]
19. Vorstman JA, Spooren W, Persico AM, Collier DA, Aigner S, et al. (2014) Using genetic findings in autism for the development of new pharmaceutical compounds. Psychopharmacology (Berl) 231: 1063-1078. [Crossref]

20. Mesibov G, Shea V, Schopler E (2004) The TEACCH Approach to Autism Spectrum Disorders. New York: Springer.

21. Edelson S (2014) Bernard Rimland's Infantile Autism: The book that changed autism. Autism Research Institute.

22. Cook KA, Willmerdinger AN (2015) The History of Autism. Furman University Scholar Exchange Narrative Documents.

23. Roman L (2015) What Are We Telling Mothers When We Say "Breast is Best"?

24. Baron-Cohen S, Auyeung B, Norgaard-Pedersen B, Hougaard DM, Abdallah MW, et al. (2015) Elevated fetal steroidogenic activity in autism. Molecular Psychiatry 20: 369-376. [Crossref]

25. Baron-Cohen S (2010) Empathizing, systemizing, and the extreme male brain theory of autism. Prog Brain Res 186: 167-175. [Crossref]

26. Mosca L, Barrett-Connor E, Wenger NK (2011) Sex/Gender Differences in Cardiovascular Disease Prevention: What a Difference a Decade Makes. Circulation 2145-2154. [Crossref]

27. Volkmar FR, Woodbury-Smith M, King BH, McCracken J, State M (2013) Practice parameters for the assessment and treatment of children and adolescents with autism and pervasive developmental disorders. Journal of the American Academy of Childhood Adolescent Psychiatry 38: S32-54.

28. Neymotin F, Nemzer L (2016) Linking autism and epilepsy. Children's Health Care 45: 84-108.

29. Bauman M, Kemper T (1994) Neuroanatomic Observations of the Brain in Autism. The Neurobiology of Autism 119-145. [Crossref]

30. Churchland PS, Winkielman P (2012) Modulating social behavior with oxytocin: how does it work? What does it mean? Horm Behav 61: 392-399. [Crossref]

31. Melke J, Botros H, Chaste P, Betancur C, Nygren G, et al. (2008) Abnormal melatonin synthesis in autism spectrum disorders. Molecular Psychiatry 13: 90-98. [Crossref]

32. Chez MG, Guido-Estrada N (2010) Immune Therapy in Autism: Historical Experience and Future Directions with Immunomodulatory Therapy. Neurotherapeutics 7: 293301. [Crossref]

33. Gesundheit B, Rosenzweig JP, Naor D, Lerer B, Zachor DA, et al. (2013) Immunological and autoimmune considerations of Autism Spectrum Disorders. J Autoimmun 44: 1-7. [Crossref]

34. Rossignol DA, Frye RE (2012) A review of research trends in physiological abnormalities in autism spectrum disorders: immune dysregulation, inflammation, oxidative stress, mitochondrial dysfunction and environmental toxicant exposures. Molecular Psychiatry 17: 389-401. [Crossref]

35. Belmonte M.K, Cook EH, Anderson GM, Rubenstein JLR, Greenough WT, et al (2004) Autism as a disorder of neural information processing: directions for research and targets for therapy. Molecular Psychiatry 9: 646-663. [Crossref]

36. Buie T, Campbell DB, Fuchs III GJ, Furuta GT, Levy J, et al. (2010) Evaluation, diagnosis, and treatment of gastrointestinal disorders in individuals with ASDs: a consensus report. Pediatrics 125: S1-S18. [Crossref]

37. Angelidou A, Alysandratos KD, Asadi S, Zhang B, Francis K, et al. (2011) Brief Report: "Allergic Symptoms" in Children with Autism Spectrum Disorders. More than Meets the Eye? J Autism Dev Disord 41: 1579-85. [Crossref]

Copyright: C2016 Neymotin F. This is an open-access article distributed under the terms of the Creative Commons Attribution License, which permits unrestricted use, distribution, and reproduction in any medium, provided the original author and source are credited. 